\title{
Self-reported Confidence of the Dental Faculty Participants of "Training Workshop on Objective Structured Clinical Examination (OSCE)"
}

\author{
Rano Mal Piryani', Suneel Piryani'2, Nitasha Sharma ${ }^{3}$ \\ Health Professions Training Committee, Universal College of Medical Sciences (UCMS), \\ Bhairahawa, Nepal
}

${ }^{1}$ Rano Mal Piryani- Professor and Head of Department of Internal Medicine, Universal College of Medical Sciences, Nepal

${ }^{2}$ Suneel Piryani- Public Health Consultant, Karachi Pakistan

${ }^{3}$ Nitasha Sharma- Associate Professor, Department of Anatomy, Universal College of Medical Sciences, Nepal

\section{ABSTRACT}

Background and Objectives: Objective Structured Clinical Examination (OSCE) is one of the assessment tools used to assess the clinical skills. Health Professions Training Committee (HPTC), Universal College of Medical Sciences (UCMS), Bhairahawa, Nepalorganized 2-days Training Workshop on OSCE in Feb 13-14, 2020 for dental faculty.The objective of this study was to assess the feedback of the participants of training workshop on OSCE and their self-reported confidence using retro-pre-questionnaire.

Material and methods:The feedback was taken onthe pretested semi-structured questionnaire comprised of four parts: A. Demographic Information, B. Overall feedback on the training workshop(closed-ended questions), C.Feedback on specific sessions conducted in the training workshop on retro-pre-questionnaire and D. Feedback on good points/strengths of the raining workshopand areas for improvement- (open-ended questions). Analysis was done with SPSS-21.

Results:The rating of the participants on training workshop for usefulness, coursecontent of training, relevance of session \& content, facilitation and overall was notable.Participants' self-reported confidence remarkably enhanced after participation in the training workshop(before vs after)on all fourskills; develop blueprint for the assessment (1.33 \pm 0.5 vs $3.33 \pm 0.50$ ), develop blueprint and test map for OSCE $(1.22 \pm 0.44$ vs $3.11 \pm 0.33)$, develop OSCE station $(1.3 \pm 0.70$ vs3.67 \pm 0.50$)$ and conductOSCE examination $(1.22 \pm 0.67$ vs $3.33 \pm 0.50)$. Participants stated "the training workshop was interactive and participatory" and suggested to include more dental related tasks in training.

Conclusion:Overall the feedback of the participants was positive and noteworthy. Participants' selfreported confidence remarkably enhanced after participation in the training workshop.

Key words: Assessment, Dental faculty, Feedback, OSCE, Retro-pre, Training workshop

\section{INTRODUCTION}

Objective structured clinical examination (OSCE) tool has continuously been used for the assessment of clinical skills since its development in 1970s [1].It is among the reliable, valid and objective methods of assessment for testing performance skills such as communication skills, history taking skills, clinical examination skills, procedural 
skills, attitude, professionalism [1-4]. It is very resource intensive and demands a lot of time to invest and great efforts to put in for implementation. Generous understanding, experience and preparation are required for the development of OSCE stations and conducting OSCE examination with success [57]. OSCE for the assessment is used in all fields of the health professional education such as medicine, dentistry, nursing, pharmacy and public health [1-2, 6, 8-9].

Hence, training health professions faculty members in developing and implementing OSCE is critical for attaining its objective [2, 6]. Health Professions Training Committee (HPTC), Universal College of Medical Sciences (UCMS), Bhairahawa, Nepal organized 2-days Training Workshop on OSCE in Feb 13-14, 2020 for dental faculty.The objective of this study was to assess the feedback of the participants of training workshop on OSCE and their self-reported confidence using retro-pre-questionnaire.

\section{MATERIAL AND METHODS}

This is a questionnaire-based study conducted byHealth Professions Training Committee, Universal College of Medical Sciences (UCMS), Bhairahawa, Nepal in Feb 14, 2020.

UCMSorganized2-days Training Workshop on OSCE in Feb 13-14, 2020. The objectives oftraining workshop were to train dental faculty of Universal College of Dental Sciences (UCDS) in how to develop/construct OSCE/OSPE station/s and conduct OSCE/OSPE examination. The course contents covered during sessions were: 1) An overview on assessment including basic principles of assessment, 2) Blueprint for the assessment including developing blueprint, 3) An overview of OSCE/OSPE, skills and competencies, 4) Blueprint for the Test and Test Map including developing Blueprint for the Test and Test Map, 5) Development of the OSCE/OPSE covering a) Develop OSCE/OSPE station profile and scenario for OSCE/OSPE, b)Prepare Instructions for examiner, examinee and patient, c) Prepare checklist and rating scale and list of resources required, d) OSCE/OSPE station review and 6) conducting OSCE/OSPE examination. Tutorial, brainstorming, activity based small group work and discussion, presentation of group work in plenary were the methods used for deliberation of training workshop.

Nine dental faculty members nominated by UCDS participated in the training workshop. The participants were divided into three groups- A, B and C for activity based small group work and discussion.

At the end of training workshop, written feedback was taken from the participants. Informed consent of the participants was obtained on semi-structured questionnaire. Ethical approval was obtained from the institutional review committee. The questionnaire designed by $\mathrm{R}$ M Piryani, principal author \& Suneel Piryani, co-author and used for the feedback of the participants faculty in training conducted earlier utilized for this study [3].

The questionnaire consists of four parts: A) Demographic Information, B) Overall feedback on training workshop, C) Feedback on specific sessions conducted in training workshop on retro-pre-questionnaire and D) Feedback on good points of training workshopand areas for improvement.

A. Demographic Information:This part was limited to get info on age, sex, experience and training received before.

B. Overall feedback on the training workshop:This part contained one closed 
ended question for rating the training workshop for its usefulness, course content, relevance of session and content, facilitation and overall rating on rating scale1-10(1= poor and $10=$ excellent).

\section{Feedback on the specific sessionsof training workshop: This part of} questionnaire was retro-pre, contained four closed ended questions on 4-point Likert scale $(1=$ Not confident, $2=$ Confident, $3=$ Very confident and $4=$ Highly confident) for their self-reported confidence before and after participation in the training workshop. The questions were i) developing blueprint (BP) for the assessment, ii) developing BP and Test Map for OSCE/OSPE), iii) developing OSCE /OSPE station and iv.) Conducting OSCE /OSPE examination.

The retro-pre-questionnaire design is one of the instruments used to evaluate the efficacy of training program. It is used to avoid the sensitivity of pretest and reduce the speculation. It assesses the learners' selfreported changes in knowledge, awareness, skills, confidence, attitudes, or behaviors [10].

\section{D.Feedback on good points/strength of} training workshop and areas for improvement: This part contained three open ended questions about the good points/strengths of sessions, area for improvement and additional comments if any. The collected data was checked for completeness, accuracy and consistency and entered in IBM SPSS version 21 for analysis. The descriptive analysis was done for the frequency, mean and standard deviation.

\section{RESULTS}

The findings are explained under four headings: A) Demographic Information, B) Overall feedback on the training workshop, C) Feedback on the specific session of training workshop on retro-pre-questionnaire and D) Feedback on good points/strengths of training workshopand areas for improvement.

\section{A. Demographic Information}

Nine faculty members of dental sciences participated in the OSCE training workshop; $6(66.7 \%)$ were males and $3(33.3 \%)$ females. The mean age of the participants was 34.22 \pm 3.30 . years (range 30-42 years). More than half $(55.6 \%)$ graduated in 2012 and rest before; majority (77.8\%) completed postgraduation after 2015 and majority (77.8\%) joined Universal College of Dental Sciences (UCDS) after 2015. The mean total teaching experience was $4.44 \pm 3.09$ years (range 6 months-11 years); the mean teaching experience after graduation was $0.44 \pm 1.01$ years (range 0 month- 3 years)and the mean teaching experience after post-graduation was $4.0 \pm 3.05$ years (range 6 month-11 years). Two third (66.7\%) of the participants received basic teachers training before, while none got OSCE related training.

\section{B. Overall feedback on training workshop}

Dental faculty members rated the training workshop on scale of $1-10$ (1= poor, 10 , excellent); rating on workshop were notable. (Table 1). 
Table 1: Rating of the participant dental faculty members on Training Workshop on OSCE.

\begin{tabular}{|l|l|c|}
\hline S. No & \multicolumn{1}{|c|}{ Item } & Rating (Mean \pm SD) \\
\hline 1 & Usefulness (Scale 1-10) & $7.67 \pm 0.50$ \\
\hline 2 & Course content (Scale 1-10) & $7.56 \pm 1.13$ \\
\hline 3 & Relevance of session \& content (Scale 1-10) & $7.78 \pm 0.44$ \\
\hline 4 & Facilitation (Scale 1-10) & $8.00 \pm 0.50$ \\
\hline 5 & Overall (Scale 1-10) & $7.67 \pm 0.70$ \\
\hline
\end{tabular}

Table 2: Self-reported confidence of the dental faculty members before and after participation in training workshop on OSCE

\begin{tabular}{|l|l|c|c|}
\hline S. N & \multicolumn{1}{|c|}{ Statement } & $\begin{array}{c}\text { Self-reported } \\
\text { confidence before }\end{array}$ & $\begin{array}{c}\text { Self-reported } \\
\text { confidence after }\end{array}$ \\
\hline 1. & $\begin{array}{l}\text { Confident to develop blueprint for } \\
\text { assessment }\end{array}$ & $1.33 \pm 0.5$ & $3.33 \pm 0.50$ \\
\hline 2. & $\begin{array}{l}\text { Confident to develop Test Blueprint } \\
\text { and Test Map for OSCE/OSPE }\end{array}$ & $1.22 \pm 0.44$ & $3.11 \pm 0.33$ \\
\hline 3. & $\begin{array}{l}\text { Confident to develop OSCE/OSPE } \\
\text { station }\end{array}$ & $1.33 \pm 0.70$ & $3.67 \pm 0.50$ \\
\hline 4. & $\begin{array}{l}\text { Confident to conduct OSCE/OSPE } \\
\text { examination }\end{array}$ & $1.22 \pm 0.67$ & $3.33 \pm 0.50$ \\
\hline
\end{tabular}

C. Feedback onspecific sessions of training workshopon retro-pre-questionnaire: The self-reported confidence on 5 statements/items were analyzed for four categories (not confident $=1$, confident $=2$, very confident $=3$ and highly confident $=4$ ) on Likert scale1-4. There was marked difference in the level of self-reported confidence of the participant dental faculty members after participation in training workshop on OSCE shown in above Table 2 .

\section{Feedback on good points /strengths of assessment sessions and areas for improvement:}

Good points /strengths of Training Workshop on OSCE:Good points /strengthsshared by the participants were: working in groups and group discussion, inclusiveness of the participants in various group activities, active involvement of all participants, good insight for developing OSCE/OSPE, team work,interaction with resource person and among participants, relevant course content, overall good learning environment and streamlined presentation by the resource person. One of the participants mentioned "Before this workshop I was not able to differentiate between MCQs, spotters and OSCE. In this workshop the vision was clear and I am able to work on it.". Another participant revealed "The workshop ignited my quest to know more about OSCE/OSPE examination pattern."

Areas for the improvement in Training Workshop on OSCE:More tasks should be included in the training workshop. More example from the dentistry related subjects needs to be included in presentation. Videos on OSCE may be included. OSCE may be demonstrated practically.One of the participants stated that the duration session 
could be shortened while other mentioned duration of workshop should be more than 2 days.

\section{DISCUSSION}

This study assessed the feedback of the dental faculty participants of training workshop on OSCE and their self-reported confidence using retro-pre-questionnaireas feedback serves guide for the improvementin the facilitation, presentation and process of conducting sessions in training [11].

The rating of the participantsof training workshop on OSCE was noteworthy for usefulness of the training, course content of the training, relevance of session \& content, facilitation done and overall rating.

Remarkable difference was noted in selfreported confidence of the participants after participation in training workshop on OSCE in i) developing blueprint (BP) for the assessment, ii) developing BP and Test Map for OSCE/OSPE, iii) developingOSCE /OSPE station and iv) conducting OSCE /OSPE examination.

Working in groups and group discussion, inclusiveness of the participants in various group activities and active involvement of all participants were among the strengths of workshop shared by the participants, while incorporation of more example and tasks dentistry related subjects and Videos on OSCE and demo on OSCEsuggested by the participants.

Other studies also reported positive feedback of the participant faculty members on trainings related to OSCE, improvement in their self-reported confidence after participation and participant faculty members from different programs such medicine, dentistry, nursing, public health recognized the importance of such trainings $[3,12,13,14]$.

\section{CONCLUSION}

From the feedback of the participantsit is obvious that they ratedtraining workshop on OSCE high for usefulness, course content, relevance and facilitation and their selfreported confidence levelsubstantially enhanced for the developing Blueprint, Test Map, OSCE/OSPE stations and conducting OSCE/OSPE examination.

\section{ACKNOWLEDGEMENTS}

We highly acknowledge the participants faculty members for their active participation and providing feedback and recognize the support of management and secretarial staffof Universal College of Medical Sciences (UCMS), Bhairahawa, Nepal.

\section{REFERENCES}

1. Shahzad A, Saeed MHB, Paiker S. Dental students' concerns regarding OSPE and OSCE: a qualitative feedback for process improvement. BDJ Open 2017; 3:1-8.

2. Hussainy SY et al. Developing a Framework for Objective Structured Clinical Examinations Using the Nominal Group Technique Journal of Pharmaceutical Education 2016; 80 (9): 158.

3. Piryani RM, Piryani S. Training Workshop on developing Objective Structure Clinical Examination (OSCE) conducted at nursing campus in Nepal: Feedback of the nursing faculty participants. Janaki Medical College Journal of Medical Sciences 2018; 6(1): 49-54 DOI:

http://dx.doi.org/10.3126/jmcjms.v6i1.20576

4. Malhotra SD, Shah KN, Patel VJ. Objective structured practical examination as a tool for the formative assessment of practical skills of undergraduate students in pharmacology. J Educ Health Promot 2013; 2: 53.

5. Objective Structured Clinical Examination Manual 2014. Saudi Commission for Health Specialties, Riyadh. www.scfhs.org.sa/en/Media/OtherPublication s/Documents/OSCE\%20MANUAL.p 
6. Munkhondya, TEM., Msiska G, Chilemba E and Majamanda MD. Experience of Conducting Objective Structured Clinical Evaluation (OSCE) in Malawi. Open Journal of Nursing, 2014; 4: 705-713.

7. Khan KZ, Gaunt K, Ramachandran S, Pushkar P. The Objective Structured Clinical Examination (OSCE): AMEE Guide No. 81. Part II: Organization \& Administration. Medical Teacher 2013; 35: e1447-e1463

8. Osaji TA, Opiah M M, Onasoga OA. A tool for objectivity in general nursing examination in Nigeria. Journal of Research in Nursing and Midwifery (JRNM) 2015; 4(3): 47-52.

9. Austin Z, O'Byrne C, Pugsley J,Munoz LQ Development and Validation Processes for an Objective Structured Clinical Examination (OSCE) for Entry-to-Practice Certification in Pharmacy: The Canadian Experience. American Journal of Pharmaceutical Education 2003; 67 (3): 76.

10. Program Development and Evaluation. Using the Retrospective Post Then-Pre-Design, Quick Tips \#27 [Internet]. Madison, WI: University of Wisconsin Extension; 2005 [updated 2005 Jul 25] Available at: http://www.uwex.edu/ces/pdande/resou rces/pdf/Tipsheet27.pdf.

11. Al Wahbi. The need for faculty training programs in effective feedback provision. Advances in Medical Education and Practice 2014:5 263-268 https://doi.org/10.2147/AMEP.S62889

12. Aleluia IMB, Menezes Ms, Rocha M Build an OSCE and Improve Faculty Development: A Good Experience. Journal of Modern Education Review 2014; 4(1): 35-42 Doi: 10.15341/jmer(2155-7993)/01.04.2014/005.

13. Schüttpelz-Brauns K, Nühse K, Strohmer R, Kaden JJ. Training OSCE examiners: minimal effort with far-reaching results. Medical EducationVolume October 2014; 53 (11): 1153-54 https://doi.org/10.1111/medu.1397.

14. Piryani RM, Piryani S, ShahiM.Perceived Confidence Of Participants After Attending Assessment Sessions In Faculty DevelopmentTraining.JKISTMC 2020; 2(1)3: 65-70.

\section{Correspondence to:}

DR. RANO MAL PIRYANI

Professor and Head of Department of Internal Medicine Chief Coordinator- Health Professions Training Committee

Universal College of Medical Sciences

Bhairahawa, Nepal

Email: rano.piryani@gmail.com

r piryani@hotmail.com 